\title{
O processo de desligamento laboral: vivências narradas por casais aposentados
}

\section{The process of retiring: experiences narrated by retired couples}

\section{El proceso de desvinculación laboral: experiencias narradas por parejas de jubilados}

\author{
Marcos Henrique Antunes* \\ Universidade Federal de Santa Catarina - UFSC, Florianópolis, Santa Catarina, \\ Brasil
}

\author{
Dulce Helena Penna Soares** \\ Universidade Federal de Santa Catarina - UFSC, Florianópolis, Santa Catarina, \\ Brasil
}

\section{Carmen Leontina Ojeda Ocampo Moré***}

Universidade Federal de Santa Catarina - UFSC, Florianópolis, Santa Catarina, Brasil

\begin{abstract}
RESUMO
Este artigo analisa as vivências relacionadas ao processo de desligamento laboral na perspectiva de casais aposentados. Trata-se de um estudo qualitativo, no qual participaram 06 casais que encontravam-se aposentados há, pelo menos, um ano. Os dados foram coletados por meio de entrevistas semiestruturadas, e, posteriormente, organizados e analisados, seguindo os princípios da Grounded Theory. Os resultados mostraram que o contexto de vida dos participantes foi um fator determinante na decisão de aposentadoria, visto que as referências por eles apresentadas transitavam pelas experiências de amigos, colegas de trabalho e do cônjuge se aposentando, além do cansaço relacionado às atividades profissionais e as implicações das situações de violência social. Observou-se diferentes concepções e ideias sobre os significados da aposentadoria, as quais demonstraram tanto a possibilidade de usufruir do tempo livre do trabalho e expandir as redes de contato e convivência familiar e social, quanto posicionamentos que retrataram perdas a partir do desligamento laboral e suas consequências à vida do indivíduo. Por fim, destaca-se a importância de considerar o contexto relacional do trabalhador e do aposentado na intervenção com esses públicos, com a finalidade de constituir uma apreensão abrangente das condições potencialmente facilitadoras e/ou dificultadoras da adaptação a esse período.
\end{abstract}

Palavras-chave: aposentadoria, trabalho, cônjuges, casal. 


\begin{abstract}
The present article analyzes the experiences related to retirement from the perspective of retired couples. It is a qualitative study consisting of 6 participating couples who have been retired for at least one year. Data was collected through semi-structured interviews and, further on, organized and analyzed according to the principles of Grounded Theory. The results have shown that the participants life context was a determinant factor for their decision to retire, considering the references presented by them ranged from friends, co-workers and spouses retiring experiences, added to the fatigue from the professional life and the implications of situations of social violence. Different conceptions and ideas of the meaning of retirement were observed, which demonstrate both the possibility of enjoying free time away from work and expanding social and family contact networks, as well as a more negative view concerning retirement and its consequences to the life of an individual. Last, it is important to consider the relational context of the active worker and the retiree during interventions with both groups, aiming to construct a broad apprehension of the potentially facilitator and/or hindering conditions of this period.
\end{abstract}

Keywords: retirement, work, spouses, couple.

\title{
RESUMEN
}

Este artículo analiza las experiencias relacionadas con el proceso de desvinculación laboral desde la perspectiva de parejas de jubilados. Se trata de un estudio cualitativo, que involucró a 06 parejas que llevan, por lo menos, un año de jubiladas. Los datos fueron recolectados a través de entrevistas semi-estructuradas, y posteriormente organizados y analizados siguiendo los principios de la Teoría Fundamentada. Los resultados mostraron que el contexto de vida de los participantes resultó un factor determinante en la decisión de la jubilación, ya que las referencias que presentaron, se refirieron a las experiencias de amigos, compañeros de trabajo y cónyuges que se encontraban jubilándose, además de la fatiga relacionada con las actividades profesionales y las implicancias de las situaciones de violencia social. Se observaron diferentes concepciones e ideas sobre el significado de la jubilación, que demostraron tanto la posibilidad de disfrutar del tiempo libre y de ampliar las redes de contacto y de convivencia en la familia y la vida social, como posturas que expresaron pérdidas a partir de la desvinculación del trabajo y sus consecuencias para la vida del individuo. Por último, se destaca la importancia de considerar el contexto relacional del trabajador y del jubilado en la intervención con esos públicos, con el fin de constituir una aprehensión integral de las condiciones que potencialmente facilitan o dificultan la adaptación a ese período.

Palabras-clave: jubilación, trabajo, esposos, pareja.

\section{I ntrodução}

O processo de desligamento laboral, com ênfase na aposentadoria, é um fenômeno que está sendo investigado com atenção, principalmente, na última década. Trata-se de uma temática atual, sobre a qual pesquisadores de diferentes campos do saber têm somado esforços para entender os diversos fatores envolvidos nessa experiência, destacando a necessidade de avaliar as particularidades de cada caso e do contexto no qual se apresenta (Denton \& Spencer, 
2009; França, 2014; Zanelli, 2015). Este movimento acontece, sobretudo, em função do significativo contingente de aposentados e idosos que estão presentes na população mundial, haja vista a elevação significativa do índice desse público em países subdesenvolvidos, como é o caso do Brasil, conforme os dados apresentados pelo Instituto Brasileiro de Geografia e Estatística (2011) acerca do último censo demográfico nacional.

De acordo com Fouad e Bynner (2008), a vida profissional é composta por sucessivos estágios que englobam desde o ingresso no mercado de trabalho - o que comumente ocorre na juventude - até a desvinculação em virtude da aposentadoria. Para Zanelli (2012), a aposentadoria caracteriza-se como uma das transições que ocorrem na vida pessoal/profissional do indivíduo, localizando-se entre o montante de mudanças que compõem o desenvolvimento humano. Esses apontamentos convocam a pensar na processualidade da construção da trajetória profissional, contendo desafios específicos a serem enfrentados em cada etapa.

Ao descrever os estágios de desenvolvimento de carreira, Schein (1993) considerou que a aposentadoria configura-se como o último momento desse processo, sendo possível que ainda no estágio anterior, denominado de "desligamento", o indivíduo depare-se com a aproximação desse período de sua vida e, paulatinamente, inicie a preparação para efetivá-lo. Contudo, segundo o autor, esta afirmativa está longe de ser uma regra, e há casos nos quais o indivíduo estabelece um verdadeiro embate com a aposentadoria, reagindo de maneira defensiva, de modo a postergar ou negar o desligamento.

Cabe ressaltar também que o trabalho é um importante elemento que possibilita o desenvolvimento e a organização da vida, sendo o principal meio pelo qual as pessoas conquistam a realização profissional e a subsistência. No entanto, em virtude dos preceitos capitalistas que estruturam o funcionamento societário contemporâneo, o trabalho passou a receber uma conotação expressivamente econômica, sendo exaltado pela sua função de produção e manutenção social, de modo que a identidade do indivíduo esteja intrinsecamente atrelada ao que ele realiza e empreende (Borges \& Yamamoto, 2014; Zanelli, Silva \& Soares, 2010).

Nessa direção, percebe-se uma dissociação entre trabalho e aposentadoria, sendo o primeiro entendido como mecanismo de produção e a segunda percebida como inatividade. Por essa via, a aposentadoria passa a ser revestida de significados que a distorcem e estigmatizam, tais como exclusão, ociosidade e inatividade, tornando-se alvo de preocupação e de comportamentos que visam a sua evitação (Moreira, 2011; Santos, 1990; Soares, 2002; Souza, Matias, \& Brêtas, 2010). Exemplo disso pode ser constatado no 
estudo desenvolvido por Selig e Valore (2010), o qual identificou que, dentre os motivos apontados por um grupo de pré-aposentados em relação à continuidade da inserção no contexto produtivo após a aposentadoria, estava o fato de tentar postergar as decorrências subjetivas relacionadas ao desligamento do trabalho. Isto significa, segundo as autoras, que a definição pela ruptura ou pela continuidade impõe um conflito psíquico no qual está presente a necessidade de pertencimento e o medo de tornar-se inútil e/ou de se perder.

A aposentadoria, conforme assinalam França, Menezes, Bendassoli e Macedo (2013), possui um caráter multideterminado, visto que a tomada de decisão sobre a efetivação desse período está interligada a diversas questões, tais como o vínculo laboral, o campo das organizações, o cenário demográfico atual e os fatores individuais. Neste último aspecto, estão incluídas as relações familiares e sociais. Assim, entende-se o desligamento laboral como um processo que engloba desde o período no qual o indivíduo percebe a iminência da aposentadoria até a efetivação e a potencial adaptação à mesma, configurando-se um evento que ocasiona mudanças no estilo de vida do indivíduo e influência sobre os níveis de bem estar e satisfação (Wang \& Shi, 2014).

Com base no apresentado, este artigo foi desenvolvido com o objetivo de analisar as vivências relacionadas ao processo de desligamento laboral na perspectiva de casais aposentados. Compreende-se que as vivências são os sentidos gerados por meio da relação com os objetos e com os outros, envolvendo os afetos e os valores estabelecidos pelo sujeito, constituídas em relações alteritárias que permitem ao sujeito retirar-se de si, colocar-se em outros lugares e transformar-se, em um processo dinâmico que culmina na assimilação do seu meio (Bakhtin, 2003). Desse conceito é possível depreender, principalmente, que as vivências provocam a produção constante de significados no transcorrer da vida, na medida em que despertam novos pontos de vista.

Considerando-se as transformações sóciodemográficas mundiais supracitadas, a relevância deste estudo circunscreve-se na demanda de desenvolvimento e revisão de políticas e práticas promotoras do envelhecimento ativo, conforme proposto pela Organização Mundial de Saúde (2005). Dessa maneira, aponta-se que a apreensão das vivências que compuseram o processo de desligamento laboral de casais aposentados possibilita dar visibilidade às particularidades de como sujeitos distintos percebem e experienciam este evento, o que, por sua vez, gera subsídios para intervenções em diferentes áreas da psicologia, especialmente, nas ações direcionadas ao contexto de carreira e trabalho. Cabe ainda informar que os dados apresentados são resultantes de uma pesquisa maior que buscou compreender as 
repercussões da aposentadoria na dinâmica relacional familiar na perspectiva do casal (Antunes, 2014).

\section{Método}

\subsection{Participantes}

Participaram deste estudo 12 pessoas (06 casais), com estrutura familiar tradicional, composta pelos subsistemas conjugal/parental e fraternal/filhos. Os participantes tinham idades entre 56 e 68 anos, residiam em meio urbano e nível de escolaridade entre Ensino Técnico e Doutorado. A renda mensal dos casais variou entre 10 e 40 salários mínimos, sendo a média correspondente a 18 salários mínimos vigentes.

Em relação às ocupações exercidas por esses indivíduos, conforme pode ser averiguado na Figura 01, constatou-se que, com exceção do casal B, cuja esposa informou ser "do lar", em todos os demais ambos os cônjuges desenvolveram carreiras com atividades externas ao ambiente familiar. Acerca do período em que encontravam-se aposentados, este variou de 01 ano e 06 meses a 15 anos, dado que se refere à efetivação do desligamento laboral, a partir da qual foram cessadas as atividades profissionais. Cabe salientar que tanto a esposa do casal $B$ quanto a esposa do casal $F$ mencionaram não receber benefício previdenciário no momento em que ocorreu a pesquisa, sendo que, no segundo caso, a participante havia apenas finalizado sua carreira, como profissional autônoma, na área comercial. 


\begin{tabular}{|c|c|c|c|c|c|}
\hline Identificação & Cônjuge & Idade & Escolaridade & Profissão exercida & $\begin{array}{c}\text { Tempo de } \\
\text { aposentadoria }\end{array}$ \\
\hline \multirow[t]{2}{*}{ Casal A } & Marido & 60 & Mestrado & Professor & 03 anos \\
\hline & Esposa & 62 & Ensino Técnico & $\begin{array}{c}\text { Técnica de } \\
\text { Enfermagem }\end{array}$ & 11 anos \\
\hline \multirow[t]{2}{*}{ Casal B } & Marido & 63 & Doutorado & Professor & $\begin{array}{c}01 \text { ano e } 06 \\
\text { meses }\end{array}$ \\
\hline & Esposa & 68 & Graduação & Do Lar & Não se aplica \\
\hline \multirow[t]{2}{*}{ Casal C } & Marido & 63 & Especialização & Economista & 05 anos \\
\hline & Esposa & 59 & Especialização & Empresária & 07 anos \\
\hline \multirow[t]{2}{*}{ Casal D } & Marido & 64 & Especialização & Bancário & 08 anos \\
\hline & Esposa & 56 & $\begin{array}{c}\text { Superior } \\
\text { Incompleto }\end{array}$ & Tesoureira & 15 anos \\
\hline \multirow[t]{2}{*}{ Casal E } & Marido & 58 & Especialização & $\begin{array}{l}\text { Gerente na área } \\
\text { de Informática }\end{array}$ & 02 anos \\
\hline & Esposa & 57 & $\begin{array}{l}\text { Superior } \\
\text { Completo }\end{array}$ & $\begin{array}{l}\text { Analista de } \\
\text { Sistemas }\end{array}$ & 04 anos \\
\hline \multirow[t]{2}{*}{ Casal F } & Marido & 64 & $\begin{array}{c}\text { Superior } \\
\text { Completo } \\
\end{array}$ & $\begin{array}{c}\text { Gerente na área } \\
\text { Comercial }\end{array}$ & 05 anos \\
\hline & Esposa & 59 & $\begin{array}{l}\text { Superior } \\
\text { Completo }\end{array}$ & Relações Públicas & 05 anos \\
\hline
\end{tabular}

Figura 01: Caracterização dos participantes da pesquisa.

A respeito da constituição familiar, todos os casais possuíam descendentes, cujo número variou entre 01 e 02 filhos, com idades entre 24 e 36 anos. Reitera-se que, do total de 06 casais, 02 ainda estavam convivendo com os filhos na residência da família, os quais dependiam dos pais, inclusive, financeiramente.

\subsection{Instrumentos}

A coleta de dados foi realizada por meio de entrevistas semiestruturadas, cujo roteiro era composto por: i) dados sóciodemográficos e de identificação dos participantes; ii) questões norteadoras referentes à experiência de aposentadoria.

\subsection{Procedimentos de Coleta de Dados e Cuidados Éticos}

Acerca dos preceitos éticos, todos os procedimentos relativos ao desenvolvimento deste estudo foram orientados pelas regras de pesquisa com seres humanos, conforme disposto na Resolução $\mathrm{n}^{\circ}$ 466/2012 do Conselho Nacional de Saúde/Ministério da Saúde. O parecer favorável para execução da pesquisa foi emitido pela Instituição de Ensino na qual os autores estão vinculados, sob $0 \mathrm{n}^{\circ}$ 313.979. 
Para acesso e convite aos participantes da pesquisa foi utilizada a técnica Bola de Neve (Denzin \& Lincoln, 2000), de modo que o contato com eles ocorreu intermediado pelas indicações das redes de relações pessoais dos pesquisadores e do grupo de pesquisa ao qual pertencem. $O$ primeiro contato com os casais foi estabelecido via telefone, sendo que, nesse momento, foram informados sobre os objetivos da pesquisa e convidados para participar dela, além de proceder-se à verificação dos critérios estabelecidos para a mesma.

A coleta de dados aconteceu nas residências dos participantes e foi realizada unicamente pelo primeiro autor deste artigo. Antes de iniciar as entrevistas, o pesquisador voltou a elucidar os objetivos do estudo e verificar o interesse dos indivíduos em participar dele e conceder informações sobre sua trajetória pessoal. A partir disso, foi realizada a leitura e assinatura do Termo de Consentimento Livre e Esclarecido.

As entrevistas semiestruturadas foram conduzidas individualmente, ou seja, em momentos distintos com cada um dos cônjuges. Os dados coletados foram gravados mediante a autorização dos participantes, e, posteriormente, transcritos.

\subsection{Procedimentos de Análise dos Dados}

Os dados foram organizados e analisados qualitativamente por meio do método da Grounded Theory, desenvolvida por Strauss e Corbin (2008). O processo de análise dos dados envolveu as seguintes etapas: i) interação com os dados por meio de leituras sucessivas do material coletado; ii) codificação aberta, na qual os dados foram examinados, desmembrados e, posteriormente, agrupados; iii) criação das categorias, as quais foram nomeadas de acordo com os aspectos nucleares evidenciados e a representação dos códigos tal como foram agrupados; iv) codificação axial, sendo este o processo de estabelecer subcategorias e elementos de análise a serem abordados em cada uma das categorias; v) fenômeno central, o qual se refere à triangulação entre os dados coletados e a literatura, sendo possível sustentar a compreensão do fenômeno investigado neste estudo.

O conjunto de dados obtidos a partir da coleta de dados possibilitou a elaboração da categoria de análise denominada "Vivências no processo de desligamento laboral", a qual integra aspectos que revelam experiências e situações em torno da experiência de desligamento do trabalho, retratando tanto o período anterior à sua efetivação quanto o momento em que houve a consolidação da aposentadoria. Nesse sentido, foram identificadas, também, as concepções relacionadas à aposentadoria na perspectiva dos casais, possibilitando, assim, uma melhor contextualização desse processo. Esta categoria de análise congrega as seguintes subcategorias: i) 
Vivências e expectativas relacionadas à aposentadoria antes de sua efetivação; ii) Vivências na efetivação da aposentadoria; iii) Concepções relacionadas à aposentadoria. Cumpre informar que a organização dessa categoria emergiu das falas dos entrevistados, e pretende demonstrar a singularidade e a riqueza das vivências descritas por eles em torno do fenômeno de estudo, cujos elementos de análise serão apresentados e discutidos a seguir.

\section{Resultados e Discussão}

A primeira subcategoria, intitulada "Vivências e expectativas relacionadas à aposentadoria antes de sua efetivação", congrega um conjunto de elementos que balizaram a decisão pelo desligamento laboral dos casais envolvidos neste estudo. Nesse sentido, cinco participantes relataram que a percepção da experiência de aposentadoria de amigos e colegas de trabalho foi um fator que demonstrou a aproximação desse período em suas vidas, bem como proporcionou contato com o tema e, ainda, evidenciou a necessidade de preparação. Os relatos permitiram verificar que a aposentadoria de pessoas da rede de relações do indivíduo possibilita a visualização das vivências do outro e, sendo estas positivas, podem servir como modelo e, inclusive, estimular o desligamento do trabalho. Contudo, problematiza-se que esse tipo de situação denuncia a ausência de conhecimento e preparação em torno desse período, o qual deveria ser alvo de reflexão ao longo de todo o processo de desenvolvimento pessoal e profissional do indivíduo, conforme mencionado por França e Soares (2009).

Alguns participantes narraram que mantinham expectativas e exerceram pressão para que os seus parceiros também se aposentassem, com o intuito de unirem-se a eles, que já estavam vivenciando tal condição. Nessa perspectiva, analisa-se que o fato de o cônjuge já estar aposentado pode configurar-se como um aspecto influenciador na decisão do parceiro que encontra-se em vias de efetivar seu desligamento. Embora os cônjuges que sofreram a influência desses posicionamentos não tenham relatado nada a esse respeito, é possível questionar quais foram os efeitos dessa interferência na tomada de decisão de aposentadoria. Assim, chama a atenção como as atitudes, especialmente de interesse e de persistência dos parceiros, podem tornar-se fatores precipitadores do rompimento do vínculo de trabalho, pressionando para que isso ocorra, sem que reflita, necessariamente, a escolha do próprio indivíduo.

Estes dados permitem considerar a importância do desenvolvimento de projetos de futuro na aposentadoria, sendo que esses devem atender tanto às necessidades de âmbito individual quanto conjugal, 
respeitando as respectivas decisões e desejos. Sobre esse quesito, convém ressaltar o estudo desenvolvido por França (2009) com "top" executivos brasileiros e neozelandeses, no qual verificou-se que, especialmente no caso dos brasileiros, os executivos cujos cônjuges influenciaram positivamente na decisão de aposentar-se apresentaram maior percepção de ganhos em relação a esse período. O cansaço relacionado às atividades laborais foi outro aspecto destacado por três participantes como uma condição que influenciou a definição pela aposentadoria. Os relatos expressaram que este elemento estava relacionado, principalmente, às exigências formais e de ordem burocrática das atividades que executavam e da Instituição na qual estavam atuando. Com base nisso, percebe-se que a aposentadoria surge como uma alternativa quando o trabalhador encontra-se fatigado mediante as suas demandas profissionais. De acordo com Zanelli et al. (2010), a ótica da produtividade sob a qual se estabelecem as relações laborais na contemporaneidade pode ser geradora de sobrecarga e estresse nos trabalhadores. Assim, é possível questionar os efeitos que a busca excessiva pela produção ocasiona na trajetória profissional do indivíduo, uma vez que a decisão pela aposentadoria pode associar-se à insatisfação com o volume de trabalho ao qual encontra-se submetido.

Três casais citaram que a diminuição das obrigações financeiras com a família foi um aspecto relevante em sua decisão pela aposentadoria. De acordo com os depoimentos, observou-se que, para esses participantes, o trabalho ocupou um lugar central na garantia dos meios de subsistência individual e familiar. Relataram ainda que ter alcançado metas estabelecidas anteriormente e contar com filhos independentes favoreceu o processo decisório. Esse resultado corrobora o que havia sido identificado por Szinovacz, Deviney e Davey (2001), ao descreverem que os compromissos econômicos com a família influenciam diretamente na definição pelo rompimento do vínculo laboral.

As vivências de violência social foram mencionadas por um casal como a principal razão de seu desligamento laboral. Cabe informar que esse casal trouxe diversos relatos sobre a questão durante a entrevista, tendo presente que eles possuíam negócios particulares no período que antecedeu a aposentadoria, e tanto a empresa quanto os seus proprietários sofreram diferentes formas de violência, tais como roubo e perseguição. As experiências sobre as quais discorreu esse casal evidenciaram o sofrimento relacionado à insegurança e à desproteção social, posto que esses fatores interferem no contexto do trabalho e na qualidade de vida do indivíduo. Constatou-se que, para esses participantes, o cessamento das atividades profissionais representou a possibilidade de um estilo de vida mais satisfatório, sendo que a aposentadoria parece vincular-se à busca por um novo modo de organização cotidiana. Esses relatos sinalizaram, portanto, a 
necessidade de uma compreensão ampla dos motivos e motivações imbricados nessa decisão, sendo pertinente mencionar que não foi localizada na literatura discussão que tratasse da relação entre aposentadoria e violência.

Por outro lado, seis participantes enfatizaram em seu discurso que a principal expectativa em relação à aposentadoria referia-se a ter tempo livre para aproveitar a vida. Seus relatos denotavam o desejo desses indivíduos de executar atividades prazerosas e vinculadas ao lazer. Cabe mencionar que tais narrativas denunciaram uma possível dificuldade de conciliação entre o tempo destinado aos interesses pessoais e as obrigações profissionais. Nessa linha, analisa-se que a aposentadoria pode configurar-se em um momento oportuno para experiências que extrapolam o contexto laboral, pois, conforme postulam Soares e Costa (2011), os projetos relacionados ao futuro são estabelecidos em consonância com o modo pelo qual o indivíduo estabeleceu seu vínculo laboral.

Outro aspecto destacado por cinco participantes diz respeito à expectativa de dedicar mais tempo para a família, cabendo citar que as falas retrataram o contexto familiar como sendo alvo de atenção e interesse na aposentadoria, reiterando a importância dos vínculos estabelecidos neste âmbito. O estudo desenvolvido por França (2009) com "top" executivos brasileiros e neozelandeses evidenciou que, entre os preditores sociais de maior influência sobre as atitudes de aposentadoria, estão as relações familiares e de amizade. Resultados semelhantes foram encontrados em outras pesquisas (França, Menezes, \& Siqueira, 2012; Magalhães, Krieger, Vivian, Stralioto, \& Poeta, 2004), que demonstram que a aposentadoria é compreendida como um recomeço nos diversos âmbitos da vida, e que o relacionamento familiar possui lugar de destaque nos projetos estabelecidos para este período.

A segunda subcategoria, denominada de "Vivências na efetivação da aposentadoria", apresenta as situações e as experiências relatadas pelos participantes no período em que ocorreu a consolidação do desligamento laboral. Nessa perspectiva, o rompimento gradual do vínculo laboral foi o modo vivenciado por sete entrevistados. Compreende-se o rompimento gradual do vínculo laboral em relação às condições disponibilizadas ao indivíduo para vivenciar o desligamento do trabalho de maneira processual, ou seja, em meio a um conjunto de vivências relacionadas ao fenômeno, as quais podem ser proporcionadas tanto por ele quanto pelo contexto no qual está inserido. Notou-se nos relatos que este tipo de desligamento conferiu um maior limiar de escolhas ao indivíduo e favoreceu a preparação para a efetivação da aposentadoria. Assim, percebeu-se que essa perspectiva parece vincular-se estreitamente com a adaptação ao período, uma vez que o indivíduo pode dispor de meios favoráveis para o enfrentamento às transformações decorrentes do mesmo. 
Reforçando esse entendimento, constatou-se que três participantes relataram vivenciar rompimento abrupto do vínculo laboral e, nesses casos, houve a expressão de uma maior dificuldade em lidar com o desligamento do trabalho e as repercussões na vida do indivíduo. As narrativas mostraram que o rompimento das relações de trabalho, principalmente, quando ocorre de maneira inesperada, ocasiona decorrências em todo o contexto de vida do aposentado, envolvendo aspectos de saúde e dos vínculos profissionais, familiares e sociais, conforme já havia sido identificado pela literatura (Antunes \& Parizotto, 2013; França, 2014; Zanelli, 2012; Zanelli et al., 2010).

Especificamente no caso de uma participante, observou-se que a sua aposentadoria aconteceu aos 42 anos de idade, sendo que a sua fala revelou, sobremaneira, a impotência sentida mediante a definição desse processo, bem como o temor relacionado à continuidade dos projetos que ainda estava executando. Frente a isso, pode-se questionar em que medida sucede uma intensificação do impacto da aposentadoria quando o indivíduo encontra-se em uma fase ainda jovem do seu desenvolvimento. Destaca-se que, para além do término da carreira ou de uma etapa desta, as condições precipitadoras do desligamento laboral precisam ser devidamente analisadas, uma vez que fatores de ordem objetiva, burocrática e emocional encontram-se diretamente relacionados aos significados atribuídos a essa vivência. Estes resultados ratificam o que foi observado por Zanelli et al. (2010), para os quais a interrupção abrupta e/ou alienadora do trabalho pode resultar em prejuízos para a qualidade de vida do trabalhador, causando sentimentos de desamparo e desequilíbrio.

Ainda em relação às experiências na efetivação da aposentadoria, verificou-se no relato de seis participantes que estes vivenciaram um período de adaptação ao ambiente familiar, o que ocorreu, especialmente, em função da intensificação do envolvimento nesse contexto. Notou-se que esse processo ocasionou mudanças no estilo de vida e comportamento tanto do aposentado quanto de seus familiares, visto que a aposentadoria acarretou modificações no modo pelo qual o outro cônjuge, que já estava aposentado, e também os filhos haviam estruturado suas rotinas e tarefas. Constatou-se que a intensificação da presença e da participação do aposentado no ambiente familiar, bem como do contato com os integrantes desse grupo, provocou o tensionamento dos relacionamentos, em uma repercussão das transformações que emergem com o aumento da proximidade entre os integrantes, evidenciando novas demandas e tarefas que desafiam a família. Essa análise coaduna-se ao que foi exposto por Carter e McGoldrick (1995), ao mencionarem que a aposentadoria caracteriza-se como um evento estressor no ciclo de vida familiar, visto que a iminência desse período é responsável por desencadear a reorganização do sistema familiar, culminando no 
desempenho de novos papéis e funções por parte de seus componentes.

Outro aspecto relatado pelos participantes trata a aposentadoria como um momento para a retomada de antigos vínculos e estabelecimento de uma rede de novos amigos, o que estava relacionado, principalmente, à possibilidade de o aposentado estabelecer e reforçar contato com pessoas, bem como à necessidade e o interesse em realizar este movimento, haja vista que contavam com mais tempo disponível para isso. Nessa direção, analisa-se que, com a efetivação da aposentadoria, podem ocorrer alterações na dinâmica instituída com os relacionamentos sociais, sobretudo, quando os mesmos estavam firmados por meio das relações laborais. Estes resultados convergem com as constatações de Azevedo e Carvalho (2006), mostrando que o sistema de relações instituído pelo aposentado leva em conta a busca pelo pertencimento e a seleção de pessoas, de acordo com seu interesse de convivência. Ainda nesse sentido, vale destacar que, dentre os aspectos psicológicos imbricados na experiência de aposentadoria, a qualidade dos relacionamentos estabelecidos neste período constitui-se um elemento importante nas vivências que procedem do mesmo, uma vez que reflete diretamente na autoestima do indivíduo (França et al., 2013; Zanelli et al., 2010).

A terceira subcategoria, "Concepções relacionadas à aposentadoria", reúne os diversos significados atribuídos a esse período pelos casais participantes. Nesses termos, três pessoas mencionaram que a aposentadoria significava o término das responsabilidades laborais e, consequentemente, estar liberado das atividades profissionais. É oportuno enfatizar que a aposentadoria diz respeito à integração de aspectos de ordem legal, burocrática e, também, subjetiva, uma vez que tendo cumprido os requisitos, o indivíduo passa a contar com um limiar considerável de autonomia para definir o momento de efetivar o seu desligamento e sobre como deseja usufruir do tempo livre do trabalho. Santos (1990) afirma que esse período assume o significado de liberdade na vida dos indivíduos que agregam vivências positivas durante sua trajetória profissional, podendo sentir-se satisfeitos e buscar outros meios de inserção.

Outros participantes evidenciaram a concepção de que a aposentadoria é um período necessário para dar lugar aos trabalhadores jovens, retratando a finitude de uma etapa da carreira e o reconhecimento das experiências constituídas ao longo do tempo. Chamou a atenção a expressão "passar o bastão", utilizada por uma participante, haja vista que denota a preocupação com os trabalhadores mais jovens, os quais necessitam de espaço no mercado de trabalho, cujo argumento justificava, em certa medida, a sua definição pela aposentadoria. Examina-se que essa concepção pode estar associada aos preceitos capitalistas que balizam a 
estrutura social, segundo os quais os trabalhadores são divididos entre ativos e inativos. Nesse sentido, pode haver um estímulo para que os trabalhadores mais velhos aposentem-se e cedam lugar aos jovens que estão iniciando a vida laboral (Cintra, Ribeiro, \& Andrade 2010).

Também foram verificadas concepções que retrataram a aposentadoria como um novo momento da vida, e a denominaram o "projeto de ser feliz". De acordo com o relato dos entrevistados, a aposentadoria constitui-se um novo ciclo da vida no qual não haveria mais os compromissos do trabalho, e a ênfase recai sobre o indivíduo, na atenção para consigo, seus relacionamentos e anseios. A análise desse aspecto exige considerar, a priori, que essa compreensão da aposentadoria está pautada pelo contexto socioeconômico de vida dos participantes, posto que em classes sociais baixas é possível que não aconteça a interrupção de atividades laborais em virtude das necessidades financeiras relativas à conquista de meios para a subsistência individual e/ou familiar (Cintra et al., 2010; Szinovacz et al., 2001).

Levantou-se ainda a hipótese de que esses elementos possam representar dificuldades ou insatisfações em torno da ocupação exercida, assim como a primazia e o direito de gozar da felicidade neste período do ciclo vital, o que, por sua vez, parece direcionar a discussão para o interesse destes participantes em obter tempo livre para curtir a vida, reiterando uma possível dificuldade dos mesmos conciliarem as demandas profissionais com outras esferas da vida. Convém destacar que o modo pelo qual o indivíduo construiu sua trajetória de trabalho implica diretamente na apreensão e nas vivências relacionadas à aposentadoria. Assim, considera-se que a análise dos elementos que permearam a definição por uma determinada profissão, tais como o momento histórico e do desenvolvimento pessoal em que houve a escolha profissional, bem como questões contextuais que ratificam a sua permanência nesta, afiguram-se como importantes preditores de significados atribuídos ao trabalho aliado à identidade profissional e à satisfação com seus projetos de vida (Soares, 2002; Soares \& Costa, 2011).

As perdas decorrentes do desligamento laboral também foram destacadas por uma participante que, em seu relato, sinalizou as modificações transcorridas no processo de desligamento laboral com pesar, de tal modo que, durante a entrevista, chorou diversas vezes. Nesse sentido, constatou-se que a reação às perdas por ela referidas não resumiram-se ao período em que houve a efetivação da aposentadoria, mas podiam ser também percebidas no momento atual, face às suas dificuldades em reorganizar a vida. É importante analisar que a aposentadoria configura-se como um período do desenvolvimento humano, no qual ocorrem mudanças que atingem diretamente a identidade do indivíduo e podem conduzi-lo à vivência 
de um luto, sendo exemplos disso a perda do trabalho e do local onde este era desempenhado, o afastamento dos colegas de trabalho, a diminuição do contato com pessoas que se beneficiavam da atuação profissional (Antunes \& Parizotto, 2013). Observa-se que estes elementos envolvem tanto questões emocionais quanto objetivas e, portanto, integram aspectos do desenvolvimento do indivíduo que são proporcionados por meio do trabalho, bem como condições que estruturam a sua vida e rotina.

\section{Considerações Finais}

Mediante os resultados apresentados e visando responder ao objetivo deste estudo, ressalta-se que a análise das vivências que compuseram o desligamento laboral dos participantes possibilitou identificar o caráter processual da aposentadoria, tendo em vista as diferentes experiências que influenciaram as suas trajetórias ao longo do tempo. Nessa perspectiva, tendo como base os dados atinentes ao período antecedente ao encerramento das atividades profissionais, foi possível averiguar que o trabalho ocupa um espaço significativo do tempo de vida e, inclusive, regula o desempenho do indivíduo no cuidado consigo e/ou a participação em relacionamentos sociais. Por essa via, as principais expectativas e ideias relacionadas à aposentadoria refletem, sobretudo, o interesse desses indivíduos em engajar-se em outra proposta de vida na qual contassem com tempo livre disponível para realizar atividades individualmente, na família e/ou com outras pessoas de sua rede de relações. Compreende-se que esses aspectos interligam-se diretamente aos significados atribuídos ao processo pelos casais, posto que apresentaram, principalmente, a concepção desse período como um momento oportuno para o resgate e o investimento nos âmbitos da vida que não receberam atenção suficiente, ou, ainda, para a ampliação das fontes de satisfação e felicidade.

Entretanto, é plausível problematizar a concepção de aposentar-se como um "projeto de ser feliz", pois essa expressão potencializa o imaginário de que esse ato possibilita gozar a vida, distante do trabalho e de outras obrigações, sem reconhecer devidamente as repercussões que emergem a partir da transição efetivada. Isso também leva a refletir que esse ideal não considera a possibilidade de o indivíduo ter se realizado durante/com a sua carreira.

Ademais, é digno de nota o fato de que alguns participantes mencionaram não ter recebido informações e a preparação adequada para a aposentadoria. Nesses casos, a percepção da aproximação desse período ocorreu por meio do reconhecimento das experiências de pessoas da rede de relações. Desse modo, analisa-se que o tema ainda carece de visibilidade e debate nos cenários laboral e social, 
desafiando especialmente os gestores, para que possam dar ênfase a essa questão em suas políticas e ações. Nesse contexto, a orientação para aposentadoria deve articular-se com outras práticas de gestão de pessoas com a finalidade de propiciar que os trabalhadores avaliem suas trajetórias, sopesando os propósitos pessoais e o tempo alocado nos papéis que cumprem em diferentes esferas de inserção social.

Outro aspecto de destaque refere-se às vivências de violência social relatadas por dois participantes, visto que a relação entre aposentadoria e situações de violência parece ser pouco explorada, não tendo sido encontrada em estudos na área. Para tanto, ressaltase a importância de pensar as peculiaridades socioculturais que afetam o vínculo laboral e como estas interferem na decisão de aposentadoria.

No tocante ao período posterior à efetivação da aposentadoria, observou-se que a forma como acontece o desligamento influencia a adaptação ao novo momento de vida. Com base nos dados apreciados, denota-se que a ausência de preparação associada ao rompimento abrupto do vínculo laboral é capaz de ocasionar desdobramentos significativos no modo como o indivíduo se percebe e constitui projetos para a aposentadoria, dificultando a visualização de novas oportunidades.

Especificamente sobre o contexto familiar, julga-se necessário considerar que o mesmo foi apontado em diferentes etapas do processo de aposentadoria, orientando tanto a decisão pelo desligamento laboral devido ao desejo de conquistar mais tempo e se dedicar aos relacionamentos nesse espaço, quanto a iminência de mudanças que transcorrem com a intensificação do convívio conjugal e parental. Nessa direção, depreende-se que, para além dos aspectos individuais, a aposentadoria ocasiona a rearticulação da dinâmica relacional na família, exigindo que os membros desse sistema revisem a organização de seu cotidiano e estabeleçam projetos característicos para essa etapa do ciclo vital. Recomenda-se que esses elementos sejam objeto de novas investigações e, também, ponderados na intervenção com esse público, quer seja através da discussão com os aposentados, quer seja na inclusão da família em práticas de orientação.

O conjunto de dados obtidos permite analisar que a aposentadoria, distante de ser um processo linear no qual o indivíduo simplesmente encerra suas atividades profissionais e realiza a passagem para um novo momento de sua carreira, envolve uma série de ideias, expectativas e condições que retratam as particularidades do seu cenário de vida e produzem repercussões no âmbito subjetivo e também na organização cotidiana e relacional. Dessa maneira, evidencia-se que o processo de desligamento laboral é um fenômeno complexo e sua análise e compreensão necessitam, via de regra, 
serem executadas face ao contexto no qual o indivíduo encontra-se inserido.

Finalizando este artigo, cabe apontar ainda que, em termos metodológicos, acredita-se que a natureza qualitativa e o fato de ter trabalhado com diferentes protagonistas, no caso os dois membros do casal, permitiram dar voz e reconhecer versões distintas a respeito do tema e dos movimentos que ocorreram em virtude do rompimento do vínculo com o trabalho. Quanto às limitações do estudo, entende-se que estas residem no contexto socioeconômico de vida dos participantes, sendo necessário investigar como esse processo é vivenciado por sujeitos pertencentes a outros extratos sociais. Assim, é relevante que novos estudos deem continuidade a esta análise e aprofundem o entendimento das experiências de aposentadoria sob a perspectiva de outros atores.

\section{Referências}

Antunes, M. H. (2014). Entre "o mito do pijama" e "o projeto de ser feliz": as repercussões da aposentadoria na dinâmica relacional familiar na perspectiva do casal (Dissertação de Mestrado). Programa de Pós-graduação em Psicologia, Universidade Federal de Santa Catarina, Florianópolis, Santa Catarina.

Antunes, M. H., \& Parizotto, A. P. A. V. (2013). Reflexões sobre a aposentadoria: contribuições a partir das experiências de professores aposentados. Psicologia Argumento, 31(75), 769779. doi: 10.7213/psicol. argum.31.075.AO14

Azevedo, R.C., \& Carvalho, A.M.A. (2006). O lugar da família na rede social do lazer após a aposentadoria. Revista Brasileira de Crescimento e Desenvolvimento Humano, 16(3), 76-82.

Bakhtin, M. (2003). Estética da criação verbal. São Paulo: Martins Fontes.

Borges, L. O., \& Yamamoto, O. H. (2014). Mundo do trabalho: construção histórica e desafios contemporâneos. In J. C. Zanelli, J. E. Borges-Andrade \& A. V. B. Bastos (Orgs.), Psicologia, Organizações e Trabalho no Brasil (pp. 25-71). Porto Alegre: Artmed.

Carter, B., \& McGoldrick, M. (1995). As mudanças no ciclo de vida familiar: uma estrutura para terapia familiar. Porto Alegre: Artes Médicas.

Cintra, T. S., Ribeiro, D. F., \& Andrade, A. (2010). O cotidiano de aposentados que continuam trabalhando de maneira informal na indústria calçadista: percepções sobre a aposentadoria e o trabalho atual. Cadernos de psicologia social do trabalho, 13(2), 277-287. doi: http://dx.doi.org/10.11606/issn.19810490.v13i2p277-287 
Denton, F. T., \& Spencer, B. G. (2009). What is retirement? A review and assessment of alternative concepts and measures. Canadian Journal on Aging, 28(1), 63-76. doi: $10.1017 /$ S0714980809090047

Denzin, N. K., \& Lincoln, Y. S. (2000). Handbook of qualitative research. Thousand Oaks: Sage.

Fouad, N. A., \& Bynner, J. (2008). Work transitions. American Psychologist, 63(4), 241-251. doi:10.1037/0003066X.63.4.241

França, C. L. (2014). Prevenção e promoção da saúde mental, políticas públicas sobre envelhecimento ativo e educação para aposentadoria. In S. G. Murta, C. L. França \& J. Seidl. Programas de educação para aposentadoria: como planejar, implementar e avaliar (pp. 22-36). Novo Hamburgo: Synopsis.

França, L. H. F. P. (2009). Influências sociais nas atitudes dos 'Top' executivos em face da aposentadoria: um estudo transcultural. Revista de Administração Contemporânea, 13(1), 17-35. doi: 10.1590/S1415-65552009000100003

França, L. H. F. P., \& Soares, D. H. P. (2009). Preparação para a aposentadoria como parte da educação ao longo da vida. Psicologia: ciência e profissão, 29(4), 738-751. 2009. doi: 10.1590/S1414-98932009000400007

França, L. H. F. P., Menezes, G., \& Siqueira, A. (2012). Planejamento para aposentadoria: a visão dos garis. Revista Brasileira de Geriatria e Gerontologia, 15(4), 733-745.

França, L. H. F. P., Menezes, G., Bendassolli, P. F., \& Macedo, L. S. S. (2013). Aposentar-se ou continuar trabalhando?: o que influencia essa decisão?. Psicologia: Ciência e Profissão, 33(3), 548-563. doi: http://dx.doi.org/10.1590/S141498932013000300004

Instituto Brasileiro de Geografia e Estatística - IBGE. (2011). Censo Demográfico 2010: características da população e dos domićílios. Rio de Janeiro: IBGE. Retirado de https://biblioteca.ibge.gov.br/visualizacao/periodicos/93/cd_20 10_caracteristicas_populacao_domicilios.pdf

Magalhães, M. O., Krieger, D. V., Vivian, A. G., Stralioto, M. C. S., \& Poeta, M. P. (2004). Padrões de Ajustamento na Aposentadoria. Aletheia, (19), 57-68.

Moreira, J. O. (2011). Imaginários sobre aposentadoria, trabalho, velhice: estudo de caso com professores universitários. Psicologia em estudo, 16(4), 541-550.

Organização Mundial de Saúde (2005). Envelhecimento ativo: uma política de saúde. Brasília: OPAS.

Santos, M. F. S. (1990). I dentidade e Aposentadoria. São Paulo: EPU.

Schein, E. H. (1993). Carrer Anchors: Discovering Your Real Values. São Diego, CA: Pfeiffer \& Company. 
Selig, G. A., \& Valore, L. A. (2010). Imagens da aposentadoria no discurso de pré-aposentados: subsídios para a orientação profissional. Cadernos de psicologia social e do trabalho, 13(1), 73-87. doi: 10.11606/issn.1981-0490.v13i1p73-87

Soares, D. H. P. (2002). A escolha profissional: do jovem ao adulto. São Paulo: Summus.

Soares, D. H. P., \& Costa, A. B. (2011). Aposent-Ação: Aposentadoria para Ação. São Paulo: Vetor.

Souza, R. F., Matias, H. A., \& Brêtas, A. C. P. (2010). Reflexões sobre envelhecimento e trabalho. Ciência \& Saúde Coletiva, 15(6), 2835-2843. doi: 10.1590/S1413-81232010000600021

Strauss, A., \& Corbin, K. (2008). Pesquisa Qualitativa: técnicas e procedimentos para 0 desenvolvimento de teoria fundamentada. Porto Alegre: Artmed.

Szinovacz, M. E., Deviney, S., \& Davey, A. (2001). Influences of family obligations and relationships on retirement: variations by gender, race, and marital status. J ournal of Gerontology: Social Sciences, 56(1), 20-27. doi: 10.1093/geronb/56.1.S20

Wang, M., \& Shi, J. (2014). Psychological research on retirement. Annual Review of Psychology, 65(1), 209-233. doi: 10.1146/annurev-psych-010213-115131

Zanelli, J. C. (2012). Processos Psicossociais, bem-estar e estresse na aposentadoria. Revista Psicologia: Organizações e Trabalho, 12(3), 329-340.

Zanelli, J. C. (2015). Aposentadoria e pós-carreira. In P. F. Bendassoli \& J. E. Borges-Andrade (Orgs.), Dicionário de Psicologia do Trabalho e das Organizações (pp. 59-67). São Paulo: Casa do Psicólogo.

Zanelli, J. C., Silva, N., \& Soares, D. H. P. (2010). Orientação para aposentadoria nas organizações de trabalho: construção de projetos para o pós-carreira. Porto Alegre: Artmed.

\section{Endereço para correspondência \\ Marcos Henrique Antunes}

Universidade Federal de Santa Catarina

Laboratório de Psicologia da Saúde, da Família e da Comunidade

Centro de Filosofia e Ciências Humanas

Piso Térreo, Sala 9B, Campus Universitário, Trindade, CEP 88040-500, Florianópolis

- SC, Brasil

Endereço eletrônico: marcos.antunes@live.com

\section{Dulce Helena Penna Soares}

Rua Vereador Guido Bott, 88c, Santa Mônica, CEP 88035-130, Florianópolis - SC, Brasil

Endereço eletrônico: dulcepenna@terra.com.br

\section{Carmen Leontina Ojeda Ocampo Moré}

Universidade Federal de Santa Catarina

Laboratório de Psicologia da Saúde, da Família e da Comunidade 
Centro de Filosofia e Ciências Humanas

Piso Térreo, Sala 9B, Campus Universitário, Trindade, CEP 88040-500, Florianópolis - SC, Brasil

Endereço eletrônico: carmenloom@gmail.com

Recebido em: 31/08/2015

Reformulado em: 12/11/2018

Aceito em: 15/11/2018

\section{Notas}

* Doutorando em Psicologia pela Universidade Federal de Santa Catarina

** Doutora em Psicologia Clínica pela Universidade Louis Pasteur. Professora aposentada do Programa de Pós-graduação em Psicologia da Universidade Federal de Santa Catarina.

*** Doutora em Psicologia Clínica pela Pontifícia Universidade Católica de São Paulo (PUC/SP). Professora e Pesquisadora do Programa de Pós-graduação em Psicologia da Universidade Federal de Santa Catarina.

O presente trabalho foi realizado com apoio da Coordenação de Aperfeiçoamento de Pessoal de Nível Superior - Brasil (CAPES) - Código de Financiamento 001.

Este artigo de revista Estudos e Pesquisas em Psicologia é licenciado sob uma Licença Creative Commons Atribuição-Não Comercial 3.0 Não Adaptada. 